\title{
Práticas de feedback em um curso de formação de professores de língua inglesa a distância
}

\author{
Feedback practices in a distance teacher education program for English teachers
}

\author{
Fernanda Costa RIBAS* \\ Cristiane Manzan PERINE**
}

\begin{abstract}
RESUMO: Considerando o crescimento dos cursos de licenciatura na modalidade EaD no contexto brasileiro, este artigo tem por objetivo analisar os processos de feedback que acontecem em um curso de formação de professores de língua inglesa na modalidade EaD de uma universidade federal mineira. O feedback pode ser definido como comentários em forma de opinião sobre as reações de algo, com o objetivo de prover informações úteis para futuras decisões e melhorias (ENCARTA, 2007). Acredita-se que o feedback exerce um papel fundamental na EaD, uma vez que dá ao aluno uma perspectiva de seu desenvolvimento e progresso na aprendizagem da língua; é uma ferramenta importante para o desenvolvimento da confiança e autonomia dos alunos (GARRIDO, 2005), além de influenciar a motivação e a capacidade de aprendizagem (HURD, 2006). Neste artigo, serão analisadas as práticas de feedback de tutores em duas atividades de língua inglesa postadas em fóruns de discussão virtual. Os meios de fornecer feedback adotados pelos tutores, bem como as abordagens adotadas

ABSTRACT: Considering the growth of the undergraduate courses in distance education in the Brazilian context, this paper aims at analyzing the feedback processes that take place in an online English Teacher Education Program of a federal university in Minas Gerais. Feedback can be defined as comments in the form of opinion about the reactions of something in order to provide useful information for future decisions and improvements (Encarta, 2007). It is believed that feedback plays a key role in distance education, as it gives the student a perspective of development and progress in learning the language; it is an important tool for the development of students' confidence and autonomy (Garrido, 2005) and influences motivation and learning ability of students to learn a language (Hurd, 2006). In this paper, the feedback practices of online tutors will be analyzed in two tasks posted on virtual discussion forums. The means to offer feedback adopted by the tutors, as well as their approaches (comments and error correction) will be presented and discussed. It is expected that expanding
\end{abstract}

\footnotetext{
* Doutora em Estudos Linguísticos. Professora ILEEL/UFU. ORCID: https://orcid.org/0000-0002-91162501. ribasileel@gmail.com.

** Doutora em Estudos Linguísticos. Professora do IFTM. ORCID: https://orcid.org/0000-0001-6788-6959. cristiane manzan@yahoo.com.br.
} 


\begin{tabular}{|c|c|}
\hline $\begin{array}{l}\text { (comentários e correções) serão } \\
\text { apresentados e discutidos. Espera-se que } \\
\text { expandir o entendimento da relação entre } \\
\text { feedback e aprendizagem encoraje } \\
\text { tomadas de decisão mais informadas no } \\
\text { que concerne às especificidades que } \\
\text { compõem a formação de professores de } \\
\text { línguas na EaD, em seus desafios de } \\
\text { promover a reflexão e formar } \\
\text { profissionais com proficiência em língua } \\
\text { inglesa. }\end{array}$ & $\begin{array}{l}\text { the understanding of the relationship } \\
\text { between feedback and learning could } \\
\text { encourage decision making to be more } \\
\text { informed when it comes to the } \\
\text { specificities that make up the language } \\
\text { teacher education in distance education in } \\
\text { regard to its challenges to promote } \\
\text { reflection and to prepare students with } \\
\text { proficiency in English. }\end{array}$ \\
\hline 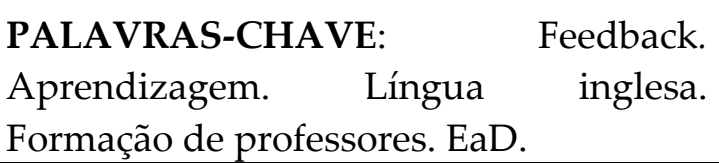 & $\begin{array}{l}\text { KEYWORDS: Feedback. Learning. } \\
\text { English. Teacher education. Distance } \\
\text { education. }\end{array}$ \\
\hline
\end{tabular}

\section{Introdução}

O que é feedback? No dicionário Houaiss (2009), há a acepção de "retroalimentação" ou "efeito retroativo", para o termo em português, indicando algo relativo a fatos passados, que modifica o que já foi feito, que retroage. Feedback é um termo que tem sua origem nas ciências naturais. Na Física, é usado em eletrônica para se referir à realimentação de um sistema, ou seja, à transferência do sinal de saída para a entrada do mesmo sistema ou circuito, resultando num aumento do nível de saída (feedback positivo) ou diminuição do nível de saída (feedback negativo). Em Psicologia, o feedback é o resultado de algum comportamento, que vai influenciar ou modificar desempenhos futuros. É estudado para minimizar conflitos entre os indivíduos. $\mathrm{Na}$ área de Administração, o termo é usado quando é dado um parecer sobre uma pessoa ou grupo de pessoas na realização de um trabalho com o intuito de avaliar o seu desempenho. Na Biologia, o feedback descreve sistemas autorregulatórios do corpo humano, por exemplo, o suor, a secreção líquida incolor, pode ser visto como feedback, ou resposta à perda de calor do corpo humano, sendo este um mecanismo primordial de regulação da temperatura do corpo. Como pode ser apreendido, o feedback em diferentes contextos permeia as relações humanas em nossa sociedade. 
No processo de ensino e aprendizagem, o termo também é amplamente utilizado. Como expresso na epígrafe que abre este artigo, as pessoas precisam de feedback. O feedback tem um papel essencial no processo de aprendizagem. Não é apenas vital, mas o modo como ele é dado e recebido impacta o processo de aprendizagem (SCHAIK et al., 2008), sendo importante tanto para professores quanto para alunos. Segundo Moscovici (2011), “feedback é um processo de ajuda para mudanças de comportamento; é a comunicação a uma pessoa, ou grupo, no sentido de fornecer-lhe informações sobre sua atuação". Ademais, para ser considerado efetivo, o feedback deve ser personalizado, específico e fornecido dentro do tempo estipulado (HYLAND, 2013). Isso significa que se o feedback é oferecido muito tempo após determinada circunstância pode não ser tão eficaz, visto que a pessoa pode já não se lembrar bem dos fatos, de como agiu ou de como se sentiu em relação a eles.

Na educação a distância $(\mathrm{EaD})$, o feedback é de suma importância para o fortalecimento das interações entre professor, tutores e alunos. Com a EaD, surgem novos paradigmas educacionais, em cuja base estão os conceitos de aprendizagem como fenômeno pessoal e social, de formação de sujeitos autônomos, capazes de buscar, criar e aprender ao longo de toda a vida e de intervir no mundo em que vivem. Ao nos referimos a esses novos paradigmas educacionais que acompanham a EaD, cabe aos linguistas aplicados e a todos aqueles envolvidos no processo de ensino e aprendizagem de línguas estrangeiras, explorar as práticas de feedback e os desafios que emergem na tarefa de auxiliar os alunos no desenvolvimento na língua-alvo, e no caso específico de um curso de licenciatura, o desafio de formar professores de línguas à distância.

Este artigo é fruto de indagações que surgiram mediante nossa atuação, em diferentes papéis, em um curso de formação de professores, ofertado na modalidade EaD - como professora, coordenadora de tutoria e tutora - no qual tivemos a oportunidade de vivenciar os processos de feedback relacionados às produções em 
língua inglesa dos professores em formação no ambiente digital. Embora a literatura em Linguística Aplicada sobre feedback seja extensa, vislumbramos que o feedback na aprendizagem de língua estrangeira, tratando-se dos ambientes virtuais ainda pode ser explorado devido às especificidades desse contexto, que difere dos contextos de outros cursos de graduação a distância. Por isso, nos propomos a investigar as práticas de feedback no referido curso, no intuito de compreender como estas poderiam impactar a produção em língua inglesa dos futuros professores. Neste artigo, analisamos duas atividades de fórum de discussão, o qual consideramos ser a sala de aula por excelência na EaD, e a interação entre alunos e tutores nesse ambiente. Identificamos as abordagens de feedback mais empregadas pelos tutores nesses fóruns, comparando duas disciplinas do curso, e cogitamos explicações e desdobramentos dessas técnicas para a formação do aluno em língua estrangeira. Com base no mapeamento das práticas de feedback dos tutores, tecemos considerações acerca de aspectos que devem estar envolvidos na formação de professores/tutores para atuar no contexto de ensino de línguas na $\mathrm{EaD}$, com especial atenção à importância da mediação pedagógica para a construção de conhecimentos na/sobre a língua estrangeira dos futuros professores.

Para cumprir com esse objetivo, o artigo será organizado da seguinte forma: primeiramente, apresentamos os pressupostos teóricos que embasaram nossa análise sobre feedback; em seguida, descrevemos a metodologia que empregamos para analisar os dados dos fóruns de discussão e fornecemos alguns detalhes do contexto de nossa investigação; na sequência, analisamos e discutimos os dados relativos às práticas de feedback dos tutores nos fóruns de discussão para, então, discutir aspectos relativos à formação docente para atuar na $\mathrm{EaD}$ no que diz respeito ao contexto de ensino de línguas. Por fim, concluímos o artigo com considerações acerca dos resultados de nossa investigação e futuros encaminhamentos. 


\section{0 feedback no ensino e aprendizagem de línguas à distância}

Para Juwah et al. (2004), o feedback ${ }^{1}$ é de grande valia tanto para professores quanto para alunos. Se, por um lado, pode gerar informações que podem ser usadas pelos alunos para melhorar sua aprendizagem e suas conquistas, por outro, pode ajudar os professores a modificar suas práticas de ensino em resposta às necessidades dos alunos. Para os autores, prover feedback é inegavelmente uma forma de avaliar os alunos e, quando atende a esses dois propósitos acima citados, torna-se uma forma de avaliação formativa, visto que focaliza mais o processo de aprendizagem do que simplesmente os resultados obtidos.

Para que o feedback de fato surta efeitos na aprendizagem, é crucial considerar o uso que o aluno faz do feedback emitido pelo professor, ou seja, como o interpreta e quais as ações que toma a partir desse feedback. Isso porque, como ressalta Encarta (2007), o feedback está relacionado à tomada de decisões. Trata-se de comentários em forma de opinião sobre as reações a algo, com o objetivo de prover informações úteis para futuras decisões e melhorias. Entretanto, por vezes, o feedback traz informações difíceis de serem interpretadas pelos alunos, por exemplo, quando estas são muito vagas ou quando o objetivo de uma tarefa não foi completamente assimilado pelo aluno.

Ao discorrer sobre a distância entre o feedback e o que o aluno faz a partir dele, Black e William (1998) descrevem que os fatores que influenciam a recepção de uma mensagem de feedback e a decisão pessoal sobre como responder a ela incluem crenças sobre o objetivo da aprendizagem como um todo, sobre a própria capacidade de responder a essas atividades, sobre os riscos envolvidos em responder de vários modos e sobre como a aprendizagem deveria ocorrer. Desse modo, defendemos que

\footnotetext{
1 Para as considerações que fazemos nesta seção, nos valemos de definições de feedback referentes tanto ao contexto presencial quanto ao contexto de aprendizagem mediada por computador e ao contexto à distância.
} 
qualquer modelo de feedback deve levar em consideração o modo como os alunos interpretam e usam a informação do feedback.

Shute (2008) classifica o feedback em formativo ou corretivo, distinção essa que consideramos relevante no contexto EaD no sentido de analisar os efeitos dessas práticas no comportamento dos alunos. O feedback formativo é a informação comunicada para o aprendiz com a intenção de modificar seu comportamento ou seu modo de pensar, objetivando uma melhoria no aprendizado. Pode, portanto, modificar significativamente os resultados a serem alcançados pelo aprendiz, dependendo da forma como é fornecido. Para que possa produzir resultados significativos, deve-se pensar em fatores como tempo, quantidade de informação e, sobretudo, linguagem utilizada (SHUTE, 2008). Já o feedback corretivo é definido como qualquer reação do professor, que transforma, sinaliza desaprovação ou pede uma melhora na produção do aprendiz (CHAUDRON, 1977). Acreditamos que ambos os tipos de feedback sejam válidos e igualmente importantes na aprendizagem de uma língua. $\mathrm{O}$ que define qual tipo de feedback deve ser empregado será a situação de aprendizagem e os personagens envolvidos nela.

Juwah et al. (2004) elencam sete princípios para uma boa prática de feedback, os quais eles acreditam serem úteis para educadores que objetivem melhorar sua prática no sentido de prover aos alunos feedback efetivo: a) facilita o desenvolvimento de autoavaliação (reflexão) na aprendizagem, para desenvolver estratégias de modo a encorajar os alunos a assumir um papel mais ativo na aprendizagem; b) encoraja o diálogo com professores e colegas em torno da aprendizagem, o qual provê informações adicionais que ajudam a desafiar os alunos a reavaliar seu conhecimento e crenças; c) ajuda a clarificar o que é um bom desempenho - objetivos, critérios e resultados esperados, ou seja, ajuda os alunos a assumirem o objetivo da tarefa como seu); d) provê oportunidades para preencher a lacuna entre o desempenho atual e o desejado, o que pode transformar o feedback recebido em ação; e) disponibiliza 
informações de alta qualidade para os alunos sobre sua aprendizagem, desde que sejam relevantes às necessidades dos alunos; f) encoraja crenças motivacionais positivas e autoestima, isto é, afeta como os alunos se veem e, consequentemente, o que e como aprendem; e g) provê informação aos professores que podem ser usadas para modelar o ensino - eles podem avaliar sua contribuição para o progresso dos alunos. Esses sete princípios evidenciam o quanto se torna crucial pensar em como professores e/ou tutores elaborarão seus comentários de forma que estes incentivem (e não desestimulem) os alunos a se autoavaliarem, se autocorrigirem e reescreverem suas produções (quando for o caso), fazendo com que tomem um posicionamento ativo em relação ao seu processo de aprendizagem.

Em contexto de instrução assistida por computador, feedback é definido por Abreu-e-Lima e Alves (2011) como a informação apresentada ao aprendiz logo após qualquer insumo com o propósito de modelar suas percepções. Nessa definição, vemos novamente que o feedback permite colocar o aprendiz como altamente responsável por sua aprendizagem. Para Paiva (2003, p. 4), o feedback é “tradicionalmente identificado como resposta do professor (tutor, computador) a um aprendiz, motivada por alguma ação relacionada à aprendizagem desse aprendiz", ou ainda, uma "reação à presença ou ausência de alguma ação". A autora define o feedback no contexto da interação on-line como "reação à presença ou ausência de alguma ação com o objetivo de avaliar ou pedir avaliação sobre o desempenho no processo de ensino-aprendizagem e de refletir sobre a interação de forma a estimulá-la, controlála, ou avaliá-la". Destaca-se em sua definição, não só o aspecto de aprendizagem, mas também a interação, pois no contexto virtual, a interação entre os envolvidos na situação de instrução é também objeto de avaliação. Ademais, não existe na definição da autora menção a termos como aprendiz, aluno, professor, tutor ou mesmo computador, de modo que, em sua visão, o feedback pode também ser fornecido por 
um colega ou mesmo por alguém não inserido no ambiente de aprendizagem propriamente dito.

Especificamente referente ao contexto $\mathrm{EaD}$, a função de dar feedback é, geralmente atribuída a um tutor que, portanto, é responsável por um dos processos centrais na aprendizagem dos alunos e nas conquistas acadêmicas (NORTHCOTT et al., 2015). É ele responsável por avaliar o aprendiz, considerando os pontos positivos e os pontos a melhorar na atividade proposta, tendo em vista aperfeiçoá-la e, ao mesmo tempo, aproximar o aluno do professor e dos demais alunos e, consequentemente, do curso, fazendo com que se sintam verdadeiramente numa sala de aula, mesmo estando geograficamente separados. No ambiente virtual, os alunos podem se sentir isolados ou excluídos, não percebendo a presença do professor ou tutor. Isso porque a sala de aula on-line não conta com os mesmos sinais não verbais como na comunicação face a face (SCHWARTZ; WHITE, 2000).

Portanto, Hurd (2006) destaca que em cursos à distância, além de informar sobre o processo de aprendizagem, o feedback pode influenciar a motivação e a capacidade de aprendizagem dos estudantes. Para a autora, o feedback pode ser usado para sustentar a motivação dos alunos, e como tal, pode exercer papel significativo em iniciativas para melhorar o suporte dado aos alunos e conter os índices de evasão, que são grandes, principalmente nos primeiros meses de qualquer curso.

Ao mesmo tempo em que exerce um papel fundamental na EaD, o feedback traz também vários desafios. Dentre eles, Garrido (2005) destaca: a) pensar em como não ser intrusivo e não inibir os alunos; b) considerar que alunos têm suas próprias visões sobre o feedback que eles precisam e como este deve ser oferecido pelo tutor; c) analisar que o feedback pode ser mal interpretado, havendo perigo de discrepância entre o que o aluno quer e precisa e o que o tutor provê.

Referente à área de ensino e ao aprendizagem de línguas, o feedback dará ao aluno uma perspectiva de seu desenvolvimento e progresso na aprendizagem da 
língua e o auxiliará no desenvolvimento da confiança e autonomia (MAIA; MATTAR, 2008). É reconhecido ainda que o feedback pode promover o desenvolvimento do aluno na LE, para que construa conhecimento e para que reflita sobre sua experiência de formação no curso (GARRIDO, 2005).

Com base em nossas leituras, principalmente de Garrido (2005), Ros i Solé e Truman (2005), propomos a seguinte esquematização dos fatores envolvidos no processo de feedback quando se pensa a aprendizagem de línguas em ambientes virtuais:

Figura 1 - Resumo esquemático do termo feedback.

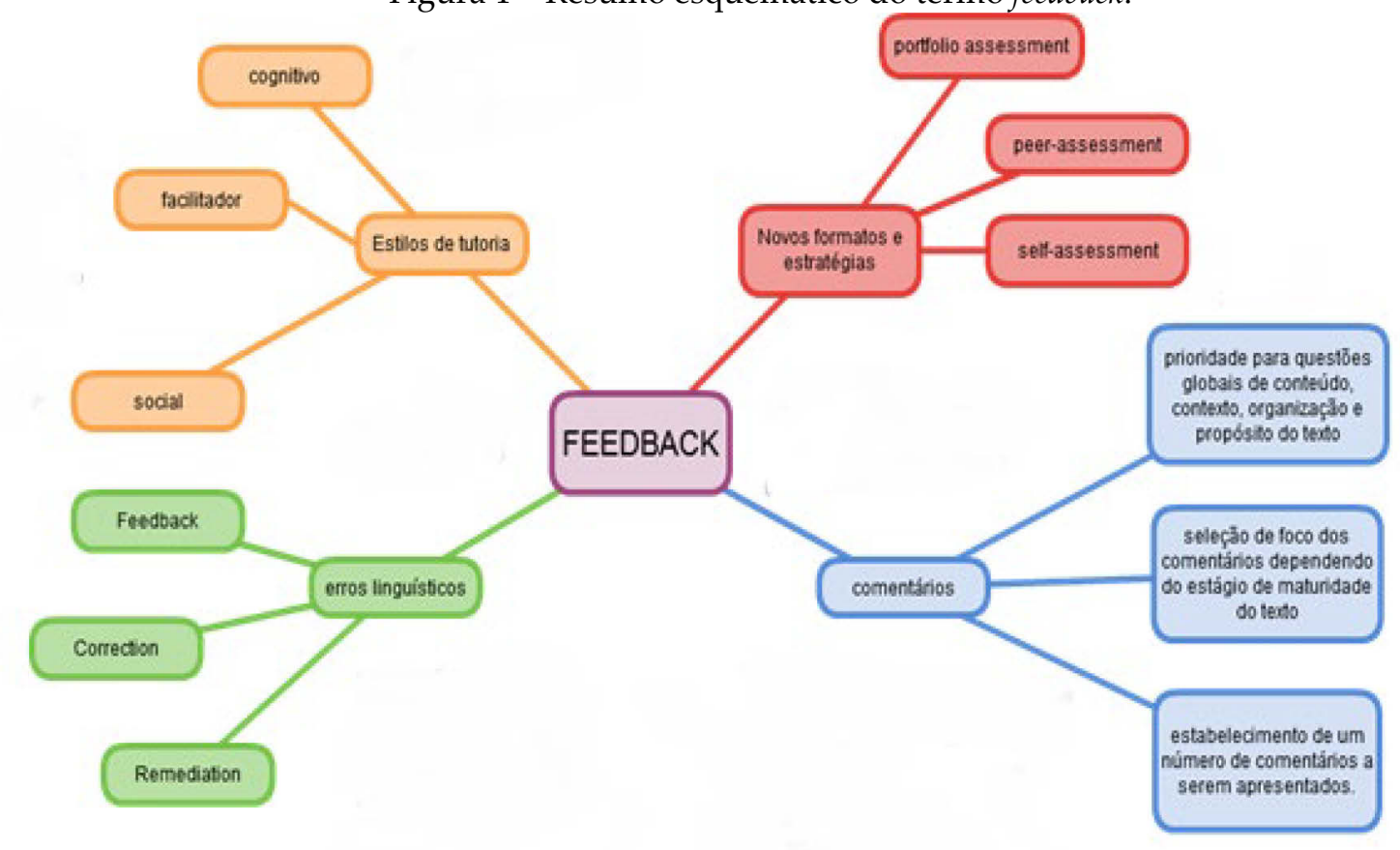

Fonte: elaborada pelas autoras.

Como pode ser observado na figura 1, o feedback depende, primeiramente, dos estilos de tutoria adotados, que podem ser de três tipos: cognitivo, quando se concentra na construção de conhecimento sobre a língua, com foco na acuidade (accuracy-focused); facilitador, quando o tutor guia os alunos na realização de tarefas e medeia as interações, atuando como participante do processo de aprendizagem dos alunos; social, quando encoraja trocas sociais entre os alunos, tendo como foco, 
portanto, a fluência e não tanto a acuidade na língua-alvo (fluency-focused). Esses estilos não precisam ser vistos como excludentes, mas complementares. Os tutores podem, assim, alternar seus estilos de atuação entre cognitivo, facilitador e social em um curso em decorrência do tipo de tarefa proposta aos alunos.

Em ambientes virtuais de aprendizagem, o feedback pode adquirir novos formatos e estratégias. Ele pode ocorrer por meio de um portfólio, no qual o aluno faz uma coletânea das atividades realizadas durante um curso e registra suas impressões sobre elas. Pode ocorrer ainda por avaliação em pares (peer-assessment), em que um aluno avalia e auxilia o outro, ou por autoavaliação (self-assessment), que encoraja a autonomia do aluno em refletir e avaliar seu próprio desempenho.

O feedback pode ser realizado por meio de comentários, os quais trazem sugestões mais gerais ao aprendiz, ou seja, uma visão global de seu desempenho nas tarefas. Estes são geralmente discursivos e individualizados, apresentam linguagem informal e acentuam aspectos específicos nas tarefas que exigem revisão. Eles têm foco no aluno, auxiliando-os a construírem significado, o que tende a facilitar o processo de aprendizagem da língua-alvo.

Quando tem foco específico em erros linguísticos, o feedback é do tipo corretivo, sendo geralmente mais padronizado, com uso de códigos de correção. Dessa forma, reforçam-se estratégias usadas pelos alunos para gerenciar sua aprendizagem, levando-os a revisar suas produções e lidar com erros. A correção pode ser de três tipos: feedback, que consiste em informar os aprendizes sobre a existência de erros e deixá-los descobri-los e repará-los de forma independente; correção (correction), que provê um tratamento ou informação que leva o aluno à revisão e à correção de seu erro; e remediação (remediation), que provê aos alunos informações que permitam que eles revisem ou rejeitem uma regra incorreta que eles adotaram, induzindo-os a revisar sua representação mental da regra e evitar a recorrência desse tipo de erro. 
A figura 1 dá uma ideia da complexidade envolvida no processo de feedback na EAD em relação ao ensino e à aprendizagem de uma LE. Ao fornecer feedback, o tutor ou professor precisa se atentar ao estilo e às estratégias que irá adotar, procurando mesclar comentários e diferentes formas de correção de erros e pensando na linguagem que irá empregar de forma que o feedback possa ser bem aproveitado pelo aluno.

\section{Metodologia}

Os dados que serão apresentados neste artigo foram coletados no curso de Licenciatura em Letras/Inglês e Literaturas de Língua Inglesa à distância², ofertado por uma universidade federal no estado de Minas Gerais. Hospedado na plataforma virtual Moodle ${ }^{3}$, o curso foi parte do Plano Nacional de Formação de Professores da Educação Básica (Parfor) ${ }^{4}$, voltado para professores em exercício na rede pública da educação básica que não tivessem formação superior na disciplina em que atuavam em sala de aula. Com tal programa, o governo objetivou oferecer a esses profissionais a oportunidade de obter a formação exigida pela Lei de Diretrizes e Bases da Educação Nacional (LDB). Na referida universidade, a primeira turma foi implantada em $2011 \mathrm{e}$ concluída em 2015. O curso atendia quatro polos, nas cidades de Uberlândia, Uberaba, Araxá e Patos de Minas. A equipe do Parfor contava com professores conteudistas (que elaboravam os materiais), professores formadores (que ministravam as disciplinas), tutores presenciais e tutores à distância, um coordenador geral e um coordenador de tutoria.

Os dados apresentados correspondem a duas disciplinas distintas: "Língua inglesa: habilidades integradas com ênfase na compreensão oral", oferecida no terceiro período e "Língua inglesa: práticas discursivas da academia", oferecida no quinto

\footnotetext{
${ }^{2}$ Para maiores informações sobre o curso: http://www.cEaD.ufu.br/content/graduacao-em-letras-ingles.

${ }^{3}$ Para maiores informações: https://moodle.org/?lang=pt br.

${ }^{4}$ Para maiores informações: $\underline{\text { http://www.capes.gov.br/educacao-basica/parfor. }}$
} 
período. À época da disciplina do $3^{\text {o }}$ período, o curso contava com oito tutores, sendo dois atuantes em cada um dos quatro polos. Por sua vez, quando a disciplina do 5o período foi ministrada, o curso contava com apenas quatro tutores. O quadro de tutores foi reduzido, devido à evasão dos alunos no curso.

Escolhemos analisar disciplinas de Língua Inglesa do curso, com foco em diferentes habilidades, tais como compreensão oral e habilidade de escrita. Visto que o curso é dividido em oito períodos, escolhemos, ainda, como critério para a análise, disciplinas ofertadas em diferentes momentos do curso.

Foram analisadas duas atividades de fórum de discussão, uma de cada uma das disciplinas citadas. Na disciplina "Língua inglesa: habilidades integradas com ênfase na compreensão oral", a atividade analisada foi um fórum de discussão intitulado "That's me", em que os alunos deveriam se apresentar e citar informações pessoais, tais como nome, profissão e cidade, dentre outras, em inglês. Em seguida, deveriam comentar os textos dos colegas.

Na disciplina "Língua inglesa: práticas discursivas da academia", foi analisada a atividade do fórum intitulado "Understanding the Genre Essay", em que os alunos deveriam escolher um dos três tópicos apresentados (a) What makes language learning so difficult?; b) Will modern technology, such as the internet ever replace the book or the written word as the main source of information?; c) Education is the single most important factor in the development of a country. Do you agree?), escrever um parágrafo e postá-lo. Além disso, deveriam comentar o texto de um colega.

Após a leitura dos fóruns de discussão, organizamos as postagens de alunos e tutores em tabelas, de modo a elencar as atividades produzidas pelos alunos e o feedback dado pelos tutores às postagens. A partir dessa tabela e com base no referencial teórico exposto na seção 2 (GARRIDO, 2005; ROS I SOLÉ; TRUMAN, 2005), criamos uma categorização, atribuindo a cada uma dessas postagens, o tipo e o meio de feedback utilizado pelo tutor, suas respectivas subcategorias e o número de ocorrência, ou seja, 
quantas vezes determinado tipo de feedback pôde ser encontrado nos dados, como detalharemos na seção a seguir.

\section{Análise e discussão dos dados}

Nesta seção, apresentamos um mapeamento das práticas de feedback observadas no Curso de Letras/EaD, tomando como referência duas disciplinas de língua inglesa oferecidas no terceiro e quinto períodos do curso, respectivamente.

Na figura a seguir, a partir de nossa interpretação dos dados, esquematizamos os meios em que ocorreu o feedback nas atividades do Curso de Letras/Inglês EaD:

Figura 2 - Meios de fornecer feedback aos alunos.

Meio de Feedback

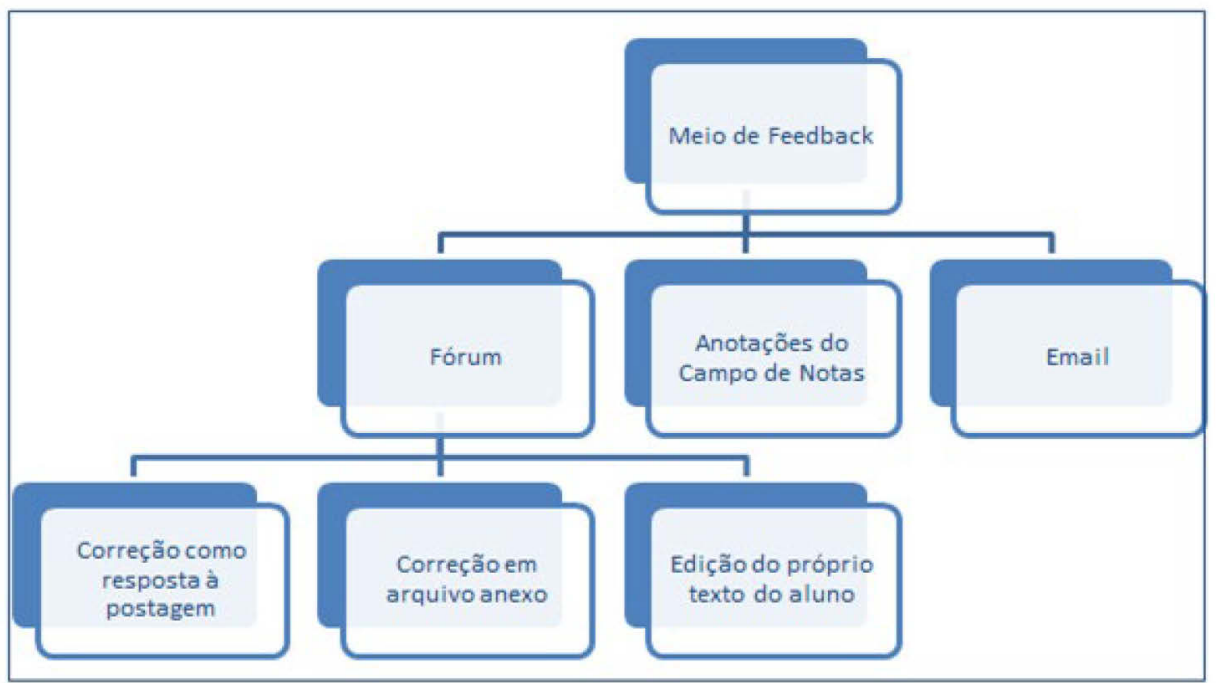

Fonte: elaborada pelas autoras.

O meio mais utilizado pelos tutores para fornecer feedback foi o próprio fórum de discussão no qual as atividades eram realizadas. Com base na análise dos dados das duas disciplinas ${ }^{5}$, concluímos que o feedback via fórum ocorreu de três modos

\footnotetext{
5 Todas as práticas de feedback analisadas ocorreram na modalidade escrita.
} 
distintos: a) correção em resposta à postagem do aluno, em que o tutor responde à postagem do aluno no próprio fórum, de modo que todos conseguem visualizar os comentários e correções; b) correção em arquivo anexo, na qual o tutor utiliza a resposta ao fórum para anexar um arquivo (no formato Word), com o texto de postagem do aluno corrigido e seu feedback; c) edição do próprio texto do aluno, nesse caso, o tutor utiliza da função "editar texto", a qual lhe é acessível por ser um usuário cadastrado como tutor, e faz modificações diretamente no texto que o aluno postou.

O segundo meio de feedback mais utilizado pelos tutores se deu por anotações no campo de notas, que é um espaço reservado no AVA para comentários na planilha de notas. Embora houvesse indicações de feedback via e-mail, porque os tutores, em alguns momentos, expressaram nos fóruns que enviariam feedback aos alunos por email, não tivemos acesso a esses dados por serem mensagens privativas. Por essa razão, esses dados não foram analisados. Diferentemente do feedback que ocorre no fórum, nas anotações no campo de notas e via e-mail, o feedback é privativo, ou seja, somente o aluno pode visualizá-lo. Os gráficos a seguir são uma representação visual dos meios de feedback identificados, respectivamente, nos fóruns das duas disciplinas:

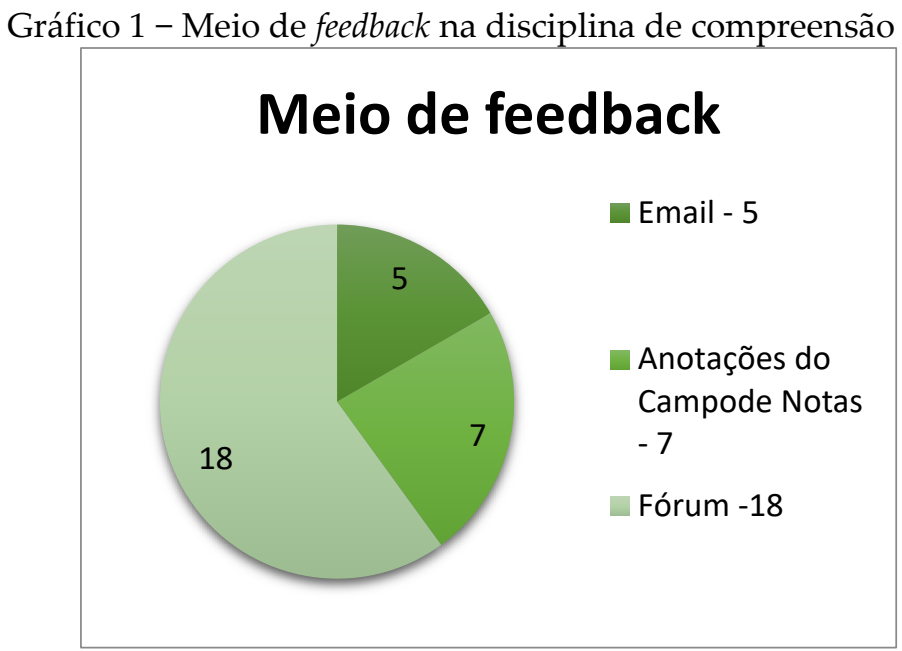


Gráfico 2 - Meio de feedback na disciplina de práticas discursivas.

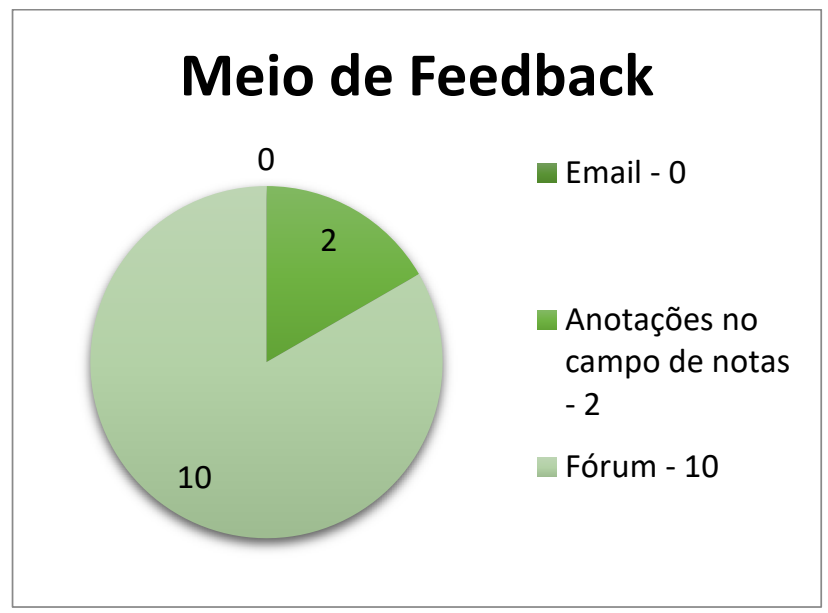

Os tutores tinham liberdade para decidir sobre dar o feedback em língua materna (LM) ou língua estrangeira (LE). Visto que são discutidas neste artigo disciplinas cujo foco é o desenvolvimento de proficiência em língua inglesa, cremos que o feedback em LE pode contribuir mais significativamente para a aprendizagem por fornecer aos alunos mais insumo na língua-alvo. Contudo, em determinadas atividades, para facilitar o entendimento dos estudantes em relação a certos aspectos da tarefa, acreditamos que pode ser melhor fornecer o feedback em LM.

A partir de nossas leituras teóricas, tais como as citadas no arcabouço teórico deste artigo, e de nossa análise dos dados, classificamos o feedback nos fóruns de discussão em dois tipos: comentário ou correção. O comentário, feito de maneira individual ou geral (para todos os alunos) se deu nos momentos em que o tutor teceu observações no intuito de explicar um determinado tópico (por exemplo, gramatical), encorajar os alunos, prover algum tipo de informação ou atuar como interlocutor, fazendo perguntas e apontamentos de forma a estimular o diálogo no fórum e levar o aluno a fazer maior uso da LE. Distinguimos quatro tipos de comentários feitos pelos tutores nos fóruns: 
a) Explicativo - se deu quando o tutor fez alguma explicação, justificativa ou de esclarecimento sobre determinado aspecto da postagem do aluno. As explicações dos tutores, por sua vez, podem ser subdividas em três tipos: normativa - quando o tutor explana alguma regra esperada na execução da atividade, tal como postar a atividade dentro do prazo estabelecido ou atingir o número mínimo de palavras estipulado para a postagem; sociocultural - quando diz respeito a aspectos sociais e culturais pertinentes às expressões da língua inglesa; e linguístico - quando está diretamente relacionado a questões de cunho linguístico, tais como gramática.

b) Encorajador - comentário tecido com o intuito de encorajar, estimular, incentivar, motivar o aluno em relação à atividade. Aparece, frequentemente, na forma de um elogio, frases prontas, ou um incentivo a tentar de novo ou a melhorar a produção apresentada.

c) Informativo - comentário com informações de conteúdo mais geral de modo a comunicar, ensinar, aconselhar ou orientar o aluno na busca de informações extras em outras fontes.

d) Interlocutivo - tipo de comentário que visou manter a comunicação e estabelecer o diálogo no fórum, a fim de que a discussão não fosse interrompida, mas tivesse continuidade. Foi comumente encontrado na forma de perguntas do tutor dirigidas ao aluno, para que ele respondesse com uma nova postagem, dando continuidade a um assunto.

O outro tipo de feedback observado nos fóruns foi a correção. Conceituamos correção como um feedback com foco corretivo direto, que ocorreu quando o tutor, ao identificar um erro na produção dos alunos, adotou um dos dois procedimentos a seguir: a) apresentação da forma correta: o tutor mostrou ao aluno, por exemplo, a forma correta de uma palavra, comumente, na sequência do trecho em que a palavra foi escrita de forma incorreta. Assim, cabia ao aluno observar e descobrir por que o trecho estava errado ou o que estava errado; b) indicação do erro e apresentação da 
forma correta: o tutor indicou ao aluno um trecho ou palavra que continha erro, fez marcações, como sublinhar o trecho ou marcá-lo com fonte de outra cor vermelha, por exemplo, ou caixa alta e, em seguida, apresentou a forma correta. Desse modo, o aluno pôde visualizar mais claramente como se expressou e como era esperado que se expressasse. Essas duas práticas de feedback, comentário e correção, são esquematizadas na figura que se segue:

Figura 3 - Tipos de feedback.

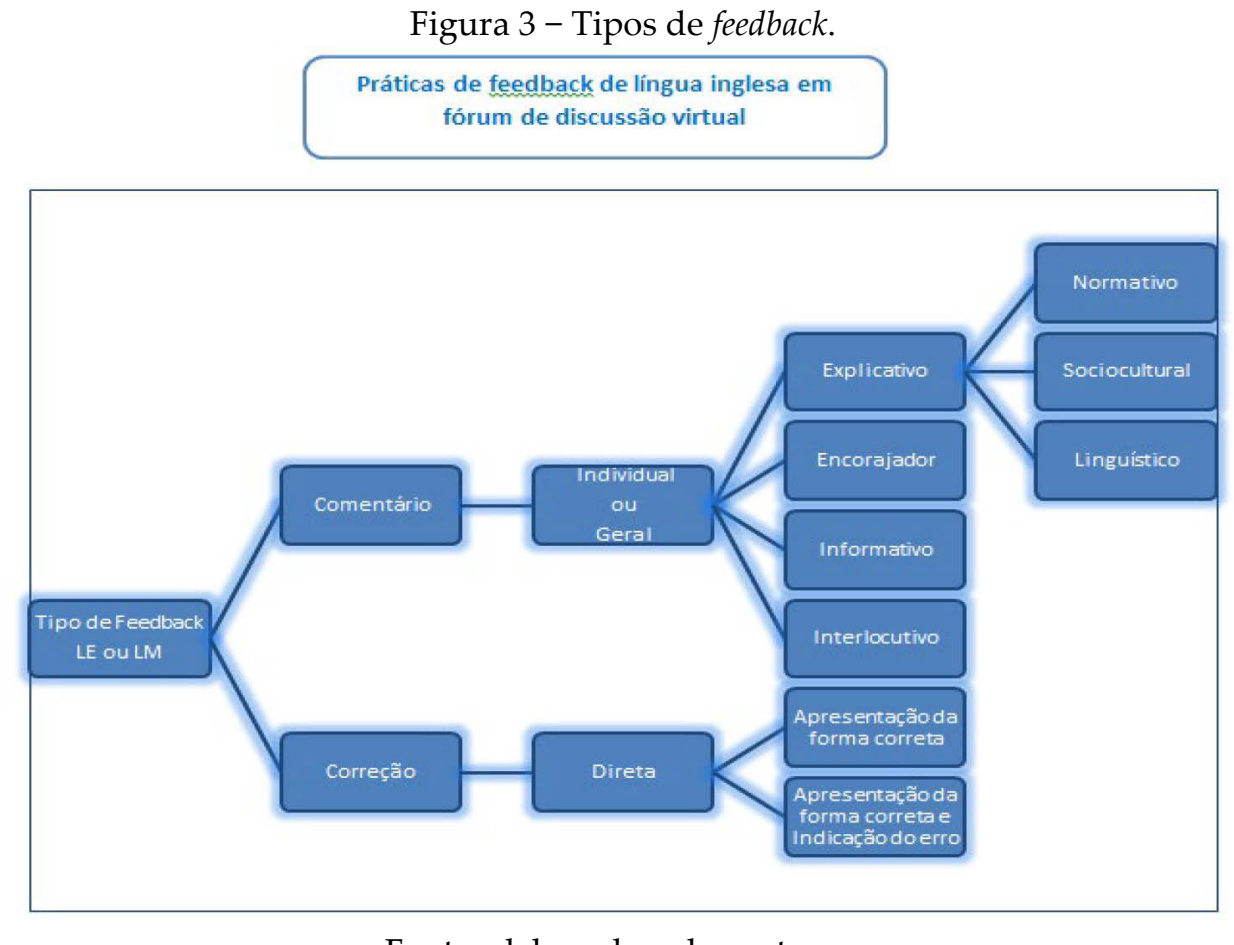

Fonte: elaborada pelas autoras.

A seguir, apresentamos algumas postagens dos fóruns feitas pelos alunos e o respectivo feedback fornecido pelo tutor de forma a exemplificar os tipos de feedback identificados em nossa análise. Observe-se esta postagem de uma aluna na disciplina de compreensão oral: 
Excerto 1

Hi, my name is F. I'm 49 years old. I'm from Araxá. I lived 15 years in Belo Horizonte, where I studied Industrial Design in college.

I'm married, and I have a daughter, 6 years old called Fernanda. My wife is a teacher of early childhood education. She's 43 years old and she works at Municipal education board. We are both public officials.

Currently I work as an employee of the administrative section of a prison of Araxá, a state agency.

I like rEaDing, watching movies and TV documentaries, traveling, listening to good music and share experiences with interesting people.

Ao responder à postagem do aluno, em seu feedback, a tutora tece um comentário individual do tipo explicativo normativo - esclarece que o aluno escreveu 100 palavras, atingindo o número de palavras exigido na atividade. Na sequência, faz um comentário encorajador, ao afirmar que este é um bom número, o que é seguido por um comentário do tipo interlocutivo, ao apresentar algumas perguntas ao aluno, como o tipo de filme e de música que ele gosta, aproveitando o comentário do aluno de que gostava de assistir filmes e ouvir música, incentivando-o, assim, a ampliar sua produção na LE:

Excerto 2

Hello $F$,

You wrote 100 words! That was really nice number!!

Let me ask you some questions...

What kind of movies do you like to watch?

And, what type of music do you like?

Xoxo, Tutora

Como vimos no referencial teórico deste artigo, o feedback do tutor só se torna eficaz com o uso que o aluno faz dele. E nesse exemplo percebemos que o aluno faz um bom uso do feedback dado pelo tutor, uma vez que, em uma nova postagem, ele agradece o elogio da tutora, responde as suas perguntas, retorna as mesmas perguntas 
para a tutora e pede que ela explique o significado de um termo que ela havia usado ao fim de sua postagem:

Excerto 3

Hello J,

Thanks for your words.

About your questions: I like to watch movies such Sci-Fi, documentaries in general, with subjects like History, Biology, Wildlife, Biography, etc. But the kind of movies I like most is about War, specially the Second World War. I love watching films of historical facts of war itself, and its consequences for us nowadays.

And about music, I like different genres as...since Classical music, until Pop Rock (but only until the 80's). I have some preferences in terms of singers and groups such as: Supertramp, Alan Parsons, Pink Floyd, Duran Duran, Simple Minds, Simply Red and others.

I hope I'd answered your questions. And about you? what kind of movies and musics do you like? And please tell me what means...Xoxo...rs

P.S.: Please correct me with my English, because I'm still very unsure. Thanks a lot.

Nesse trecho, é perceptível o anseio do aluno em ser corrigido. Conforme Garrido (2005) destaca, um dos desafios ao se fornecer feedback é considerar que alunos têm suas próprias visões sobre o feedback que eles precisam e como este deve ser oferecido pelo tutor. Pode haver, assim, discrepância entre o que o aluno quer e precisa e o que o tutor provê em termos de feedback. O excerto 3 ilustra esse problema: o aluno parece valorizar o feedback do tutor apenas quando este se dá na forma de correção a sua postagem. Em sua resposta, a tutora afirma que vai enviar o feedback em uma mensagem privada e faz um comentário do tipo explicativo sociocultural, ao explanar o que significa "xoxo". A tutora apresenta também a fonte de onde obteve informações para lhe responder. Essa é uma forma de incentivar os alunos a sempre informarem as referências bibliográficas em suas postagens de forma a evitar plágio: 
Excerto 4

Hello $F$,

I'll send the feedback in a private message as soon as possible (ASAP).

XOXO means "Hugs \& Kisses"

$\mathrm{O}=\mathrm{Hug}$

$X=$ Kiss

If you look at each letter like it was representing two people from a bird's eye view, the "O" represents the arms of those persons hugging each other while the " $X$ " is evocative of two people kissing each other.

Reference: http://www.urbandictionary.com/define.php?term=xoxo

Xoxo,

$J$

A discussão entre a tutora e o aluno continua em língua inglesa: o aluno questiona a tutora se a expressão "xoxo" é um neologismo criado a partir das novas tecnologias e se há um nome específico para essas expressões em inglês. Interessante observar que o aluno encerra sua postagem com a expressão que acabou de aprender, o que denota a importância da maneira como o feedback é dado pelo tutor no sentido de estimular mais e mais o uso da LE pelos aprendizes:

Excerto 5

$\mathrm{Hi} \mathrm{J}$,

Ok, I'll wait for your feedback.

Thanks for your explanations about the expression "Xoxo".

But I have now a new question.

It looks like that this expression is a neologism, created from the use of internet and the new technologies, I'm I wrong?

I'd wanna know more about these types of "informal terms", I know that this isn't the correct name of them, I mean, I'm sure that those expressions have a name in english, can you help me with this matter?

I hope I have made myself clear for you.

Thank you again.

And...

Xoxo,

F 
Encerrada a discussão no fórum, a tutora lança a nota do aluno e, no campo de notas, fornece feedback do tipo comentário normativo, ao retificar que o aluno escreveu o número de palavras estipulado e seguindo o prazo para realização da tarefa. Posteriormente, a tutora afirma que não há erros na escrita do aluno e faz um comentário encorajador, ao parabenizar o aluno por seu empenho, oferecendo seu apoio para auxiliar o aprendiz sempre que preciso. Ao contrário do feedback nos fóruns, em que a tutora sempre se expressou em LE, no campo de notas, ela prefere o uso da LM:

Excerto 6

Olá F, Você escreveu 100 palavras. Está dentro do número estipulado, além disso dentro do prazo estipulado da atividade. Não há erros no que tange a questão gramatical. Parabéns. Continue assim. Sempre avante! Conte comigo para o que precisar.

Outro exemplo de postagem em relação à disciplina de compreensão oral pode ser observado a seguir:

Excerto 7

Hi, my name is R. I'm 19 years old and I'm from Araxá, Minas Gerais. I work as a beautician e epilator in Centro Estético Nayara Meyra. I'm married, my husband's name's Samuel. He's 29, I don't have kids, but a have a little black dog. My parents lives in Araxá and a have two sisters, my family and Samuel's family are big. I like to sing, travel, study, cook, play music, surfing the net and go to church. It's only!

Em sua anotação no campo de notas, a tutora faz uso de diferentes tipos de feedback. Primeiramente, escreve um comentário individual do tipo encorajador afirma que a aluna fez um bom trabalho e a parabeniza pela dedicação e seriedade. $\mathrm{Na}$ sequência, faz um comentário explicativo normativo - informa que a aluna atingiu o número mínimo de palavras e seguiu o prazo de postagem. Essas anotações são escritas em LM. A partir de então, a tutora faz um feedback do tipo correção com apresentação da forma correta. Assim, ela corrige o texto da aluna utilizando a técnica 
de escrever a palavra correta entre parênteses na frente do termo que apresenta uma inadequação. Percebe-se que ela não aponta o que especificamente está errado na produção da aluna e não faz comentários explicando porque está errado ou porque deveria ser escrito de outra forma; apenas apresenta a forma correta. Como apontam Juwah et al. (2004), um bom feedback provê oportunidades para preencher a lacuna entre o desempenho atual e o desejado, o que pode transformar o feedback recebido em ação. Apenas fornecer a forma correta ao aluno pode dificultar o preenchimento dessa lacuna:

Excerto 8

Oi, R! Bom trabalho! Seu texto tem um número adequado de palavras e você procurou obedecer o prazo de entrega. Parabéns pela dedicação e seriedade! Segue a correção do seu texto: Hi, my name is Ruth. I'm 19 years old and I'm from Araxá, Minas Gerais. I work as a beautician e (and) depilator in (at) Centro Estético Nayara Meyra. I'm married, my husband's name's Samuel. He's 29, I don't have kids, but a (I) have a little black dog. My parents lives(ive) in Araxá and a(I) have two sisters. My family and Samuel's family are big. I like to sing(singing), travel (traveling), study(studying), cook(cooking), play (playing) music, surfing the net and go (going) to church. It's only(That's all)! 94 palavras

O terceiro exemplo analisado corresponde à disciplina de práticas discursivas. Seguindo a proposta da atividade, a aluna escolhe um dos tópicos sugeridos, nesse caso, descrevendo "se a tecnologia moderna, tal como a internet poderá substituir o livro ou a palavra escrita como principal meio de informação", e posta seu parágrafo:

Excerto 9

Will modern technology, such as the internet ever replace the book or the written word as the main source of information?

Everything indicates that the new technologies of communication and information not only came to stay, but to transform these processes used by mankind. Nevertheless, however great advances were found in these areas, the idea that the printed text will one day end, still seems far away. Perhaps this is due to the fact that the internet and the virtual information do not allow something which only the physical object provides, the contact with a real object that is pleasing to the human senses. Reflecting further on the subject, it seems more likely that both 
of them fit and complement each other, creating new possibilities and resources, not necessarily one alternative having to remove each other. The fact is that both have qualities that can and should be combined in order to contribute to the development of our society and the education.

Ao postar sua resposta no fórum de discussão, a tutora faz um comentário explicativo do tipo linguístico - explica o uso de alguns pronomes, conjunções e verbos que foram empregados de modo inadequado pela aluna. Posteriormente, emite um comentário encorajador, ao afirmar que gostou do conteúdo produzido pela aluna. A tutora finaliza sua postagem com um comentário informativo, sugerindo uma nova leitura à aluna:

Excerto 10

OiJ,

Na primeira frase você usa um THESE, pronome que usamos para retomar um antecedente já dito antes, mas não há algo para apoiar esta pronominalização, então ficou faltando coesão. Cuidado para não ancorar a primeira frase do parágrafo em itens lexicais do título! Nevertheless e however são sinônimos, escolha apenas um para manter. Em vez de remove, que tal EXCLUDE?

Gostei do conteúdo, concordo plenamente! Leia a Galáxia de Gutenberg, acho que você vai gostar!

A aluna aproveita o feedback recebido pela tutora para reformular seu texto e postá-lo novamente no fórum. Esta foi uma iniciativa da aluna, e não algo estabelecido como exigência da atividade. Neste exemplo, vemos claramente que a aluna explorou o feedback recebido para melhorar seu texto:

Excerto 11

Olá C ... reformulando meu texto então, com suas sugestões/orientações:

It seems that the new technologies of communication and information not only came to stay, but to transform the processes used by mankind. Nevertheless great advances were found in these areas, the idea that the printed text will one day end, still seems far away. Perhaps this 
is due to the fact that the internet and the virtual information do not allow something which only the physical object provides, the contact with a real object that is pleasing to the human senses. Reflecting further on the subject, it seems more likely that both of them fit and complement each other, creating new possibilities and resources, not necessarily one alternative having to exclude each other. The fact is that both have qualities that can and should be combined in order to contribute to the development of our society and the education.

Ficou melhor assim?

Thanks a lot!

Em resposta à aluna, a tutora abre sua postagem informalmente com uma gíria e um emoticon, parabenizando-a por sua iniciativa de reformulação do texto. Logo depois, ela apresenta um feedback do tipo comentário individual, explicativo linguístico, e sugere aprimorar a pontuação do parágrafo e algumas formas de organização de frases. Seus comentários linguísticos se aproximam mais de correção textual, mostrando atenção para questões como coesão e coerência textual. Ela não faz correções gramaticais. A tutora opta pela técnica de colocar seu texto na cor azul, diferenciando-o do texto do aluno, que aparece na cor preta. Há ainda um comentário encorajador ao fechamento utilizado pela aluna em seu texto:

Excerto 12

Aíiú!!!!!!! @)

Agora vamos acertar a pontuação, J:

Depois de Nevertheless coloque VÍRGULA e um AND no lugar da vírgula depois de AREAS. Coloque dois pontos depois de PROVIDES.

Ao usar EXCLUDE, coloque assim: "not necessarily one alternative having to exclude another" (ou "the other").

A frase do fechamento ficou pra lá de fluente, excelente escolha!!!!

Assim, se encerra a interação com a aluna no fórum. A tutora não utilizou o campo de notas para prover outros comentários. Constatamos que a tutora optou por dar feedback sempre em LM. 
O quarto exemplo que apresentamos é também relativo à disciplina de práticas discursivas:

Excerto 13

The new technologies are changing dramatically the life the people on the four corners of the world and raised a discussion in around of the possibility of traditional book be replaced for these new technology tools as the internet, the eletronic book and the tablet, for instance. These tools offer a good quality of rEaDing, are efficients and they have earned each time gained more and more e-rEaDers. Furthermore, it is veryeasier to make a download and $r E a D$ a book and enjoy some good rEaDing on the internet than to go the library to choose one.

(Editado por $\underline{\mathrm{L}}$ - domingo, 00:06)

Em seu feedback, a tutora utiliza a ferramenta dos fóruns do Moodle que permite editar o texto dos alunos, e corrige o parágrafo postado pela aluna por meio da edição do texto original. Ao fazê-lo, ela utiliza técnicas como colocar marcas tachadas sobre a expressão com erro, e escrever em vermelho a forma correta, na frente das expressões inadequadas. Faz, portanto, uma correção direta, com indicação do erro e apresentação da forma correta à aluna. Na sequência, em uma nova postagem, após a correção, a tutora tece comentários sobre o parágrafo. Ela faz um comentário individual e interlocutivo, pois expressa que concorda com o que a aluna escreveu sobre a praticidade da internet. A seguir, faz um comentário explicativo linguístico. Ela aproveita as correções que havia feito na postagem anterior com marcações em vermelho e retoma essas correções separadamente, com comentários sobre escolha de vocabulário e gramática. O excerto 14 exemplifica uma particularidade do feedback que deve ser fornecido quando se trata de um curso de língua estrangeira a distância. No momento de fornecer feedback, é preciso fazer referência tanto ao conteúdo quanto à forma das postagens dos alunos: 
Excerto 14

Hi, E. How are you?

I agree with you: in terms of practicality, nothing beats internet.

Please, check the hints below:

1. replaced $=$ substituído.

2. are eficiente: não há forma plural para os adjetivos em inglês.

3. earn = ganhar dinheiro através de trabalho; gain = ganhar (sentido geral).

4. more and more = cada vez mais.

5. easier = mais fácil. O comparativo de adjetivos curtos é feito com o acréscimo de 'er'. Como a palavra 'easy' termina com ' $y$ ', tira-se o ' $y$ ' e coloca-se ' $i$ '.

6. rEaDing: incontável, por isso usa-se 'some' e não 'a'.

Any questions, please write, ok?

Hugs,

$L$.

Tutora formadora.

Por fim, em uma anotação no campo de notas, a tutora faz um comentário encorajador à aluna, o que não havia feito no fórum. Elogia o texto e pede que a aluna confira as correções feitas no fórum, se colocando à disposição para esclarecer eventuais dúvidas:

Excerto 15

Hello, E. How are you? Good job!

Please, check the corrections in the fórum. Any questions, please write, ok?

Hugs, $L$

Tutora formadora.

Dentre as abordagens utilizadas pelos tutores para fornecer feedback, a mais empregada é a do tipo comentário, como podemos observar nos gráficos a seguir que comparam os tipos de feedback fornecido pelos tutores nas duas disciplinas analisadas: 
Gráfico 3 - Tipo de feedback na disciplina de compreensão oral.

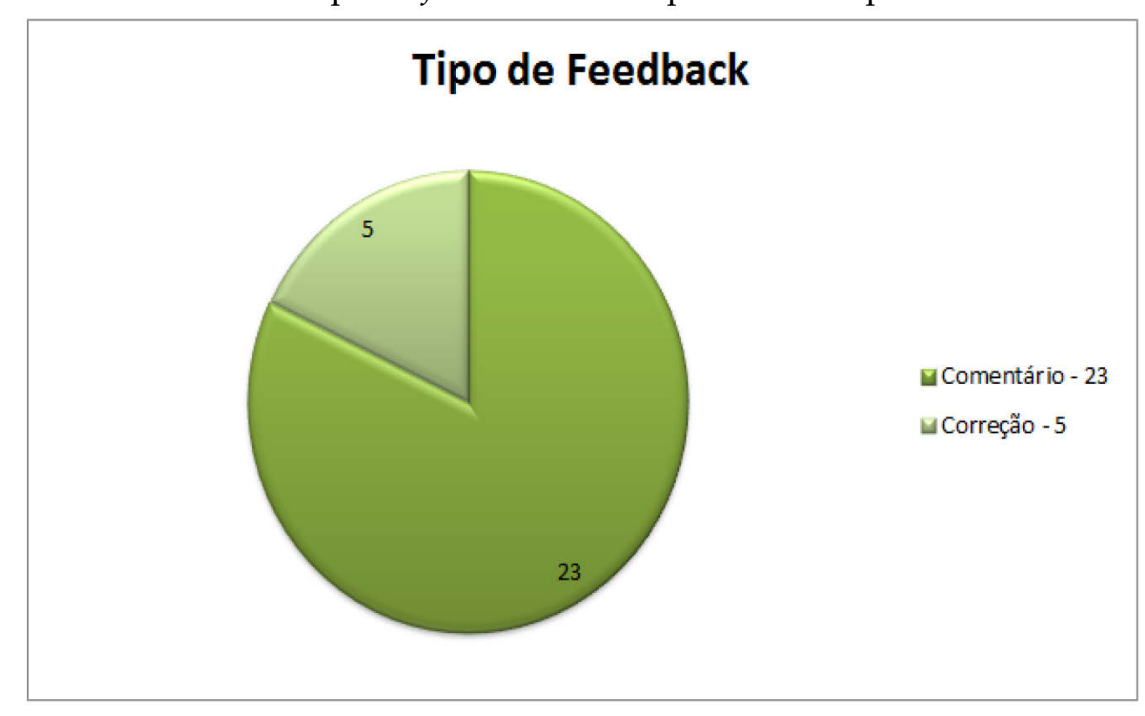

Gráfico 4 - Tipo de feedback na disciplina de práticas discursivas.

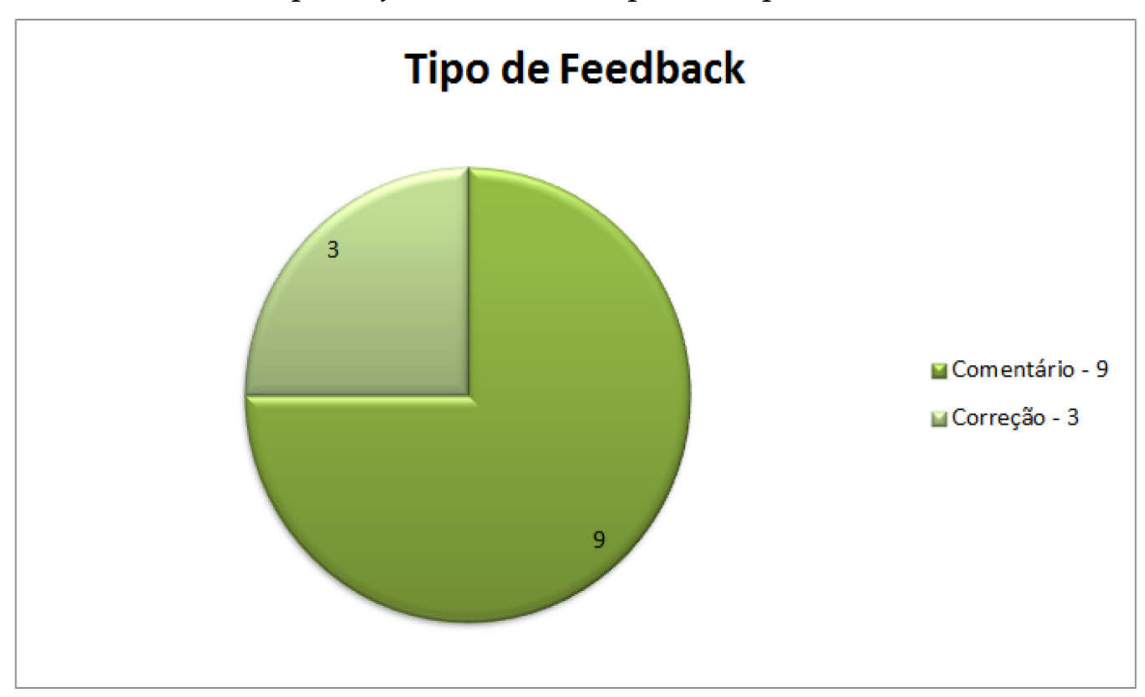

Na disciplina de compreensão oral, há enorme incidência de uso de comentários em comparação à técnica de correção. São feitas poucas correções nas produções dos aprendizes; quando estas ocorrem são do tipo direta, ou seja, ou o tutor apresenta a forma correta aos alunos (por meio de diversas técnicas, tais como escrever a forma correta em caixa alta, de outra cor ou sublinhada) ou o tutor aponta o erro cometido pelo aluno e faz as devidas correções no texto. Acreditamos que o desejável seria que as duas abordagens fossem utilizadas pelos tutores. Os tutores foram instruídos pela 
coordenação e pelo professor formador da disciplina a utilizarem das duas abordagens. Seria oportuno que os textos fossem corrigidos para que os alunos entendessem o porquê de seu erro e que tivessem opções de uso quanto às formas adequadas de expressão. No entanto, isso não ocorreu. Por se tratar de uma disciplina do período inicial do Curso de Letras/EaD, acreditamos que os tutores pela inexperiência com os recursos do Ambiente Virtual de Aprendizagem (AVA) tenham optado apenas pela apresentação da forma correta aos alunos. Outra possível explicação para tal atitude seja a preocupação dos tutores em não desmotivar os alunos, caso fizessem apontamentos que poderiam ser tomados como invasivos. Por exemplo, alguns tutores retornaram os textos aos alunos corrigidos via e-mail para evitar expor seus erros nos fóruns.

$\mathrm{Na}$ disciplina de práticas discursivas, apesar de os comentários ainda predominarem em relação à correção de erros, a postura dos tutores em relação ao tratamento de erros foi diferente: a indicação do erro, seguida da apresentação da forma correta foi a técnica mais empregada pelos tutores. Isso mostra o desenvolvimento de competências dos tutores para lidar com as especificidades requeridas para ensinar e aprender línguas no AVA. A nosso ver, a indicação do erro deve vir acompanhada da apresentação da forma correta de maneira a levar o aluno a entender e refletir sobre seus erros como meio de proporcionar a aprendizagem de estruturas da língua inglesa. Assim, o feedback cumprirá sua função formativa.

Em ambas as disciplinas, o comentário do tipo encorajador foi o mais recorrente, o que mostra a tentativa dos tutores em motivar os alunos. Como destaca Garrido (2005), um dos desafios ao se fornecer feedback aos alunos é pensar em maneiras de não ser intrusivo e inibir os alunos com os comentários ou correções que se realiza. No ambiente EaD, a interação ocorre predominantemente por meio dos fóruns. Daí a importância de usar esse espaço para encorajar os alunos a interagirem, principalmente em LE. Pela forma como os tutores se preocuparam em encorajar os 
alunos a todo o momento, sempre fornecendo elogios, mesmo quando seus textos apresentavam vários erros nos mostra que esse desafio foi superado. No entanto, vemos com certa preocupação a ênfase dos tutores nesse tipo de feedback.

De forma a cumprir o papel destacado por Garrido (2005) de promover o desenvolvimento do aluno na LE, para que construa conhecimento e para que reflita sobre sua experiência de formação no curso, colocando-o como responsável por seu processo de aprendizagem, o feedback não pode se restringir a uma função encorajadora. Como apontam Juwah et al. (2004), um bom feedback encoraja o diálogo com professores e alunos em torno da aprendizagem, dando informações que levem os alunos a uma reavaliação de seu conhecimento e crenças e à ação. Acreditamos que o feedback do tipo informativo e interlocutivo auxiliem no cumprimento desses quesitos. Os excertos 2 e 3 apresentados anteriormente ilustram o tipo de prática de feedback que acreditamos que deveria ser mais recorrente no curso.

Embora o feedback encorajador tenha sido predominante nos dados analisados, ele não aparece sozinho. Os gráficos a seguir ilustram os tipos de comentários empregados nas práticas de feedback em cada disciplina:

Gráfico 5 - Tipos de comentários na disciplina de compreensão oral.

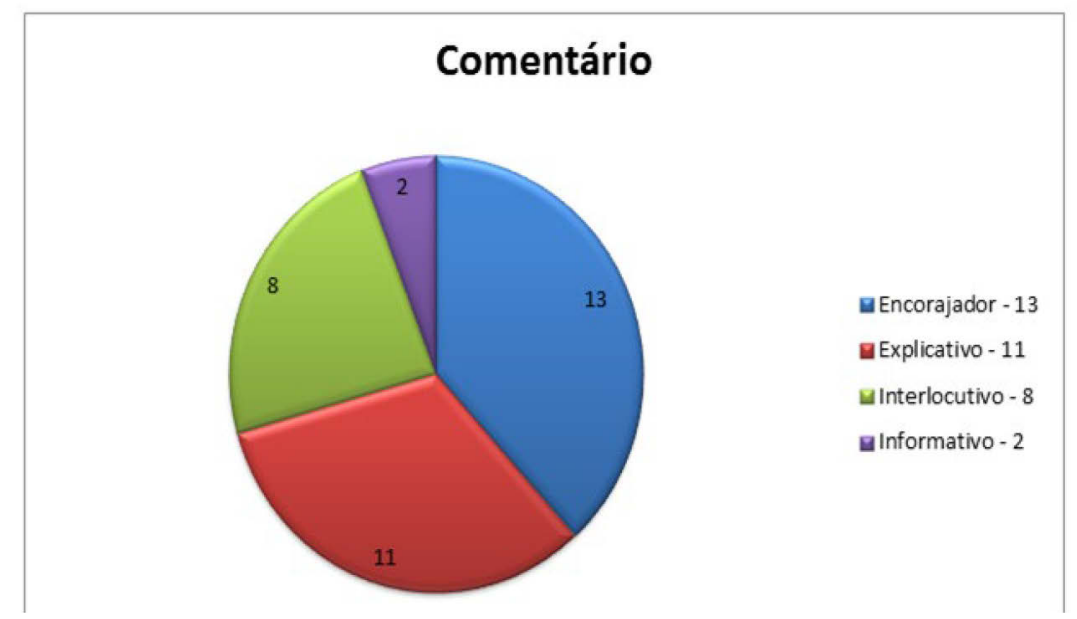


Gráfico 6 - Tipos de comentários na disciplina de práticas discursivas.

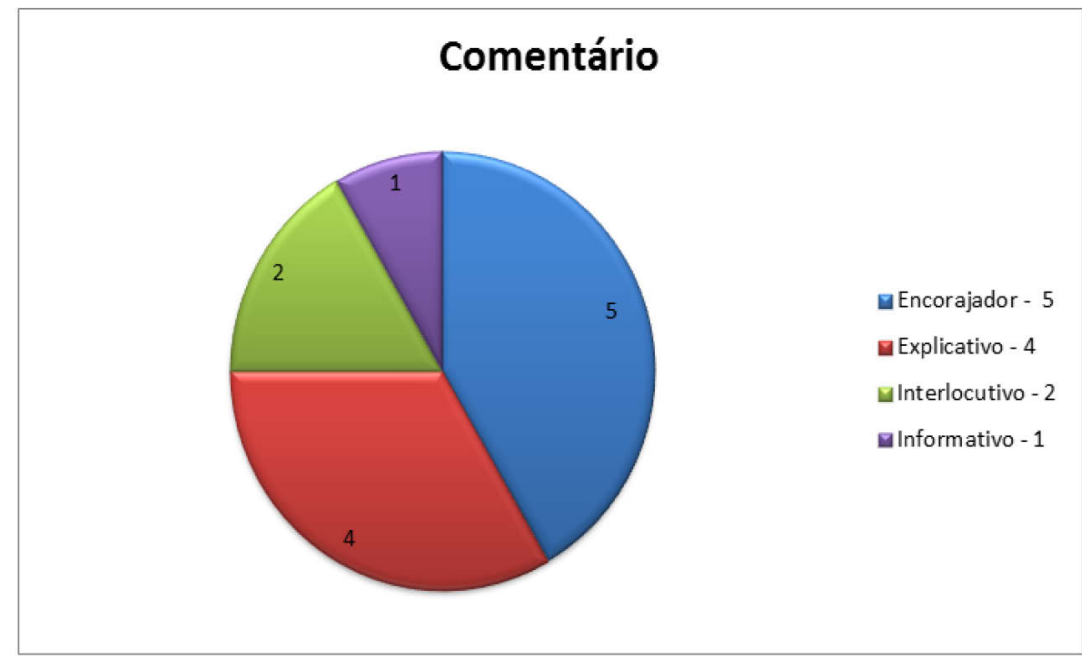

Depois do comentário encorajador, o segundo tipo de comentário mais empregado pelos tutores foi o explicativo, que ocorreu quando o tutor fez algum tipo de explicação, forneceu justificativa ou prestou esclarecimento sobre a postagem do aluno. Na disciplina de compreensão oral, o comentário explicativo mais usado é aquele do tipo normativo, quando o tutor informa ao aluno se ele cumpriu ou não os critérios da tarefa (por exemplo, número de palavras). Na disciplina de práticas discursivas, o comentário explicativo é mais do tipo linguístico, que se caracteriza por informações acerca de forma e estrutura dos textos produzidos pelos alunos, além de aspectos como coesão e coerência.

Como vimos na seção 2 deste artigo, o feedback é dado intencionando alterar o comportamento do aprendiz de forma a impactar positivamente seu aprendizado. Quando se adota uma perspectiva formativa e não apenas corretiva, deve-se estar atento à forma como o feedback é fornecido, para que este esteja adequado às necessidades dos aprendizes e das tarefas e se possa, assim, produzir resultados significativos em termos da aprendizagem da LE. A disciplina de compreensão oral foi ofertada no terceiro período do curso de Letras/EaD. Já a disciplina de práticas discursivas foi ofertada no quinto período. É compreensível que no terceiro período os alunos não estivessem tão familiarizados com as diretrizes para elaboração de textos 
em LE no curso. Daí a necessidade de o tutor fornecer feedback do tipo normativo para que os alunos pudessem adaptar seus textos aos critérios exigidos pelos professores na disciplina. No quinto período, uma vez familiarizados com os critérios, o foco do tutor recai na necessidade de adequações linguísticas para que, assim, o aluno desenvolva maior proficiência na LE.

O tipo de tarefa proposta na disciplina influencia o tipo de feedback oferecido pelo tutor. Na disciplina de compreensão oral, a tarefa requeria que os alunos discorressem sobre sua vida (That's me), que dessem informações pessoais. Nota-se, nesse caso, maior incidência do comentário interlocutivo (se comparado à disciplina de práticas discursivas). A atividade dá mais abertura para o tutor formular perguntas para conhecer melhor os alunos. Na atividade da disciplina de práticas discursivas, os alunos tinham que escrever um parágrafo dentre três temas preestabelecidos (Understanding the Genre Essay). A liberdade de escolha de expressão é menor. Além disso, há uma estrutura esperada que os estudantes tinham que se ater para desenvolver o texto. $\mathrm{O}$ tutor se atém a observar se tal estrutura foi cumprida, em corrigir erros e fornecer explicações sobre a língua. Daí identificarmos os comentários explicativos/ linguísticos. Como vimos na seção 2, o feedback pode ajudar os professores a modificar suas práticas de ensino, o que ocorre em função das necessidades dos alunos diante de determinadas tarefas de ensino.

O que esse mapeamento das práticas de feedback dos tutores no referido curso de formação de professores a distância nos mostra? Como esse conhecimento pode ser empregado de forma a favorecer avanços na área de ensino e aprendizagem de línguas e de formação de professores a distância? É o que discutimos na última seção.

\section{Reflexões a partir da análise das práticas de feedback dos tutores}

Acreditamos que investigar as práticas de feedback utilizadas pelos tutores em cursos de formação de professores de LE pode auxiliar na pesquisa de meios de 
aperfeiçoá-las, levando em conta a necessidade de uma EaD mais personalizada que contribua para a aprendizagem dos alunos, sem perder de vista duas especificidades: o contexto virtual e a produção que ocorre em LE. Segundo Castro Filho, David e Souza (2013, p. 66) "uma EaD mais personalizada quanto ao acompanhamento pedagógico dos alunos e o uso de materiais educacionais fundados numa abordagem dialógica, reflexiva e problematizadora parece preparar melhor os profissionais que o mercado atual está requerendo".

Para atuarem no curso de Licenciatura em Letras/Inglês e Literaturas de Língua Inglesa à distância, como parte do processo seletivo, os tutores tinham que obrigatoriamente ser aprovados em um curso de formação de tutores oferecido pelo Centro de Educação a Distância $(\mathrm{CEaD})$ de nossa universidade. Nesse curso, eles poderiam entender o funcionamento do ensino a distância e do ambiente virtual de aprendizagem adotado na universidade (Moodle). Esse curso era oferecido, no entanto, para todos os tutores que atuariam em cursos à distância na universidade, das mais diversas áreas (por exemplo, pedagogia, administração, matemática). Portanto, os tutores não recebiam da universidade formação específica para atuarem na área de línguas e na formação de futuros professores.

De forma a suprir essa lacuna, a coordenação de tutoria do curso de Letras realizava semestralmente reuniões pedagógicas com os tutores em que aspectos pedagógicos específicos de nossa área eram discutidos, por exemplo, como fornecer feedback às produções orais e escritas em língua inglesa dos alunos, como fazer a mediação nos fóruns de discussão, tendo em vista os objetivos de cada fórum (como discussão de teorias, compartilhamento de experiências pessoais e reflexões, postagem de textos em língua inglesa), dentre outros assuntos. Nossa intenção era que os tutores tivessem uma compreensão crítica quanto aos usos dos recursos tecnológicos e ao seu papel enquanto formadores de professores na modalidade a distância. As temáticas de discussão dessas reuniões eram feitas com base no levantamento da coordenação de 
tutoria acerca de dificuldades observadas na atuação dos tutores nos fóruns, as quais eram relatadas pelos alunos e professores formadores do curso. Dentre essas dificuldades, pudemos perceber nos dados apresentados na seção anterior aquelas relativas à ênfase em determinadas formas de feedback (por exemplo, feedback encorajador e normativo) em detrimento de outras (como o feedback informativo e interlocutivo) que poderiam estimular a autonomia para a pesquisa, a reflexão sobre teorias de ensino e aprendizagem, a construção colaborativa de conhecimentos sobre a língua inglesa e a criticidade dos professores em formação, aspectos esses que entendemos serem exigidos de um profissional para atuar na contemporaneidade.

Acreditamos que essas iniciativas de formação continuada são essenciais para provocar reflexões entre os tutores acerca de especificidades da aprendizagem de línguas à distância e da formação de professores, de forma que eles possam rever constantemente suas crenças e práticas de ensino. Dentre essas especificidades, Ribas (2018) destaca o fato de as interações no AVA serem mais pautadas na escrita, ao contrário das interações que ocorrem no contexto presencial que privilegiam encontros face a face, nos quais há uma resposta imediata de alunos e professor. Portanto, no contexto EAD, o feedback tende a não ocorrer de forma imediata ou síncrona, configuração essa que, como aponta Ribas (2018, p. 124):

pode trazer implicações afetivas aos alunos-professores. Por um lado, o fato de não estar interagindo face a face parece causar menos constrangimento para o aluno que se sente mais à vontade para expor sua opinião no grupo. Por outro lado, essas opiniões são registradas e, uma vez que o aluno comete um erro, este não passará despercebido, o que pode inibir a participação do aluno.

O professor/tutor precisa estar atento a essas questões afetivas, sem deixar de lado a necessidade de corrigir os erros dos alunos para que avancem no uso da LI. Como apontamos em uma publicação anterior (RIBAS; PERINE, 2016), além do 
impacto na aprendizagem de LE, os fóruns de discussão virtuais são ferramentas potenciais para estimular a interação e reflexão de professores, uma vez que "oferecem amplas oportunidades para se discutir ideias, para facilitar a reflexão e encorajar o pensamento crítico" (RIBAS; PERINE, 2016, p. 100), principalmente em torno de crenças e práticas de ensino. Nesse sentido, não somente ações de preparação dos tutores para o manuseio de ferramentas virtuais são importantes, mas também aquelas que envolvam uma "compreensão crítica relacionada aos usos que serão feitos desses recursos e ao papel do professor nessa modalidade de ensino" (CASTRO FILHO; DAVID; SOUZA, 2013, p. 69). São essas iniciativas que podem permitir, por exemplo, que os tutores promovam uma EaD personalizada (CASTRO FILHO; DAVID; SOUZA, 2013), ampliando seu conhecimento acerca dos tipos de feedback que podem ser empregados, quais são mais adequados à determinada atividade e que efeitos eles podem causar na participação dos alunos no curso e na aprendizagem de uma língua.

As dificuldades enfrentadas pelos professores/tutores em nosso curso também apontam para a necessidade de investimento em propostas de formação inicial de professores para estes lidarem com ferramentas tecnológicas e mediarem cursos de línguas à distância que estão a cada dia crescendo no Brasil e no mundo. O Curso de Graduação em Inglês e Literaturas de Língua Inglesa de nossa universidade, na modalidade presencial, já vem pensando nisso e recentemente realizou alterações no projeto político-pedagógico de forma a incluir disciplinas teórico-práticas com ênfase nos letramentos e nas tecnologias digitais. Além disso, foram inseridas na grade curricular do curso disciplinas na modalidade à distância, visando também a preparação dos futuros professores para atuarem em contextos de ensino virtuais.

\section{Considerações finais}

Neste artigo, objetivamos analisar as práticas de feedback adotadas em um curso de formação de professores de língua inglesa à distância. Saber o que é feedback, quais 
são seus tipos, descrevê-los e, até mesmo, identificá-los não garante um planejamento didático promissor. $\mathrm{O}$ ensino não pode se basear apenas em teorias, visto que o conhecimento da teoria acadêmica não resulta, necessariamente, no sucesso do trabalho docente. Como linguistas aplicados, é nosso dever explorar as realidades com as quais nos deparamos em diversos contextos educacionais em nossa sociedade, a fim de conhecendo-as poder teorizá-las na tentativa de provocar discussões que possam concretamente aperfeiçoar o ensino e aprendizagem de línguas na era digital.

Como evidenciado nos dados deste artigo, os professores em formação demonstram um anseio muito grande por serem corrigidos, o que revela o valor que atribuem ao feedback, e como o visualizam como um processo mais corretivo e avaliativo. Os tutores do curso, por outro lado, evitam fazer uso demasiado da correção (e preferem os comentários), por causa de um excesso de preocupação em não constranger os alunos. Além disso, por meio do feedback, tentam criar um ambiente acolhedor em que errar é natural, fato que pode ser confirmado pela preferência dos tutores em utilizar o feedback do tipo comentário em detrimento da correção, e pelo comentário empregado em ambas as atividades ser, majoritariamente, do tipo encorajador. Observa-se, ainda, que os tutores se expressaram mais em LE e o meio mais utilizado para feedback é o próprio fórum de discussão. Assim, conseguem estimular os alunos a interagirem na LE e registram observações que podem ser acessadas por todos os alunos, ampliando o fornecimento de insumo aos aprendizes.

No entanto, além desses resultados que vemos como positivos, percebemos também como algumas práticas de feedback dos tutores podem ser limitantes, uma vez que não estimulam o desenvolvimento de uma postura mais ativa por parte dos professores em formação. Se, por um lado, investir em feedback na forma de comentários encorajadores pode motivar os alunos a se arriscarem no uso da língua inglesa, não investir em correções das produções dos alunos pode inibir a chance de reflexão sobre os erros. Como aponta Figueiredo (2007, p. 208): 
A correção é um elemento importante no processo de ensinoaprendizagem de línguas, pois, sendo utilizada de forma adequada e sendo compreensível para os alunos, é um dos instrumentos que lhes servem de apoio na caminhada para o desenvolvimento de sua interlíngua.

Por correção adequada, o autor se refere a diferentes formas de correção, como a correção direta, a correção indireta, a autocorreção, a correção com toda a turma e a correção com os pares, as quais devem ser escolhidas sempre refletindo "o que, quem, quando e como corrigir" (FIGUEIREDO, 2007, p. 199). As ferramentas tecnológicas disponíveis no AVA "permitem aos participantes de cursos a distância a expressão e reformulação constante de seus pontos de vista, ao longo do processo educacional" (CASTRO FILHO; DAVID; SOUZA, 2013, p. 85). No entanto, isso só é possível quando há um deslocamento quanto ao papel do professor/tutor: de transmissor de conteúdos para mediador da aprendizagem dos alunos. Segundo Mauri e Onrubia (2010, p. 129), esse papel envolve proporcionar "auxílios educacionais ajustados à atividade construtiva do aluno, utilizando as TIC para fazer isso".

A formação de professores, quer seja inicial e quer continuada, a que acreditamos ser desejável numa era de novos letramentos é justamente aquela que investe no papel mediador do professor, entendendo o mediador como aquele que "poderá incentivar os colegas a buscar novas descobertas, por meio da utilização de materiais e ferramentas disponíveis no contexto em que estão inseridos"' (GABRIELLI, 2009, p. 214), quer seja virtual ou presencial.

Como proposta de encaminhamento para ações futuras, sugerimos que o mapeamento das práticas de feedback que realizamos possa ser utilizado na elaboração de cursos de formação de professores que irão atuar especificamente no ensino de LE. Dessa forma, haverá espaço para refletir acerca de meios para auxiliar os alunos, por meio das práticas de feedback, no desenvolvimento de sua proficiência na LE e em sua 
preparação como futuro professor. Cremos que uma proposta que prioriza a reflexão e a pesquisa como elementos necessários à formação do tutor de LE pode estabelecer novas possibilidades de ação de feedback na contemporaneidade.

\section{Referências}

ABREU-E-LIMA, D. M.; ALVES, M. N. O feedback e sua importância no processo de tutoria a distância. Pró-posições, v. 22, n. 2, p. 189-205, 2011. DOI https://doi.org/10.1590/S0103-73072011000200013.

BLACK, P.; WILIAM, D. Assessment and classroom learning. Assessment in education, v. 5, n. 1, p. 7-74, 1998. DOI https://doi.org/10.1080/0969595980050102. CASTRO FILHO, J. A.; DAVID, P. B.; SOUZA, C. F. Formação docente para a EAD. In: ARAÚJO, J.; ARAÚJO, N. (org.). EAD em tela: docência, ensino e ferramentas digitais. Campinas: Pontes, 2013. p. 63-88.

CHAUDRON, C. A descriptive model of discourse in the corrective treatment of learners' errors. Language learning, v. 27, p. 29-46, 1977. DOI https://doi.org/10.1111/j.1467-1770.1977.tb00290.x.

ENCARTA, J. Objectivism versus constructivism: do we need a new philosophical paradigm? Educational technology research and development, v. 3, n. 39, p. 5-14, 2007. DOI https://doi.org/10.1007/BF02296434.

FIGUEIREDO, F. J. Q. Erro e correção em textos escritos em língua estrangeira. In: PAIVA, V. L. M. O. (org.). Práticas de ensino e aprendizagem de inglês com foco na autonomia. Campinas: Pontes, 2007. p. 189-209.

GABRIELLI, K. S. O papel da mediação pedagógica em fóruns educacionais de cursos on-line de língua estrangeira. In: SOTO, U.; MAYRINK, M. F.; GREGOLIN, I. V. (org.). Linguagem, educação e virtualidade. São Paulo: Editora Unesp; São Paulo: Cultura Acadêmica, 2009. p. 209-224.

GARRIDO, C. Course design for the distance learner of Spanish: more challenges than meet the eye. In: HOLMBERG, B.; SHELLEY, M.; WHITE, C. (ed.). Distance education and languages: evolution and change. Clevedon: Multilingual Matters, 2005. p. 178194. DOI https://doi.org/10.21832/9781853597770-012.

HOUAISS, A.; VILLAR, M. de S. Dicionário Houaiss da Língua Portuguesa. Rio de Janeiro: Objetiva, 2009. 
HURD, S. Towards a better understanding of the dynamic role of the distance language learner: Learner perceptions of personality, motivation, roles and approaches. Distance education, v. 27, n. 3, p. 303-329, 2006. DOI: https://doi.org/10.1080/01587910600940406

HYLAND, K. Student perceptions of hidden messages in teacher written feedback. Studies in educational evaluation, v. 39, n. 3, p. 180-187, 2013. DOI: http://dx.doi.org/10.1016/j.stueduc.2013.06.003

JUWAH, C.; MACFARLANE-DICK, D.; MATTHEW, B.; NICOL, D.; ROSS, D.; SMITH, B. Enhancing student learning through effective formative feedback. Londres: The higher education academy generic centre, 2004.

MAIA, C.; MATTAR, J. ABC da EAD: a educação a distância hoje. São Paulo: Pearson/ Prentice hall, 2008.

MAURI, T.; ONRUBIA, J. O professor em ambientes virtuais: perfil, condições e competências. Psicologia da educação virtual. Aprender e ensinar com as tecnologias da informação e da comunicação. Porto Alegre: Artmed, 2010. p. 118-135.

MOSCOVICI, F. Desenvolvimento interpessoal: treinamento em grupo. Rio de Janeiro: José Olympio, 2011. p. 94-96.

NORTHCOTT, J. et al. Improving tutor feedback on online academic writing courses for postgraduates. EAP in a Rapidly Changing Landscape: Issues, Challenges and Solutions. Biennial BALEAP Conference. University of Leicester, p. 17-19, 2015.

PAIVA, V. L. M. O. Feedback em ambiente virtual. In: LEFFA. V. (org.). Interação na aprendizagem das línguas. Pelotas: Educat, 2003.

RIBAS, F. C. Formar professores de língua inglesa à distância: novas práticas, antigos desafios?. In: ROCHA, N.; RODRIGUES, A.; CAVALARI, S. (org.). Novas práticas em pesquisa sobre a linguagem: rompendo fronteiras. São Paulo: Cultura Acadêmica, 2018. p. 107-126.

RIBAS, F. C.; PERINE, C. M. Online discussion foruns: a tool for stimulating language teachers' interaction and reflection. Formamente, Anno XI, n. 1-2, p. 87-105, 2016.

ROS I SOLÉ, C.; TRUMAN, M. Feedback in distance language learning: current practices and new directions. In: HOLMBERG, B.; SHELLEY, M.; WHITE, C. (ed.). 
Distance education and languages: evolution and change. Clevedon: Multilingual Matters, 2005. p. 72-91. DOI https://doi.org/10.21832/9781853597770-007.

SCHAIK et al. The art of giving and receiving feedback. The Netherlands: Academy for Counselling and Coaching, 2008.

SCHWARTZ, F.; WHITE, K. Making sense of it all: Giving and getting online course feedback. In: WHITE K. W.; WEIGHT, B. H. (ed.). The online teaching guide: A handbook of attitudes, strategies, and techniques for the virtual classroom. Boston: Allyn and Bacon, 2000. p. 57-72.

SHUTE, V. J. Focus on formative feedback. Review of Educational Research, Princeton, v. 1, n. 78, p. 153-189, 2008. DOI: http://10.3102/0034654307313795 